\section{Experiences of women living with fibromyalgia: an exploratory study of their information needs and preferences}

\author{
Lubna Daraz, 1 Joy C. MacDermid, 1 \\ Lynn Shaw, ${ }^{2}$ Seanne Wilkins, ${ }^{1}$ \\ Jane Gibson ${ }^{3}$
}

1School of Rehabilitation Science, Faculty of Health Sciences, McMaster University, Hamilton; ${ }^{2}$ Faculty of Health Sciences, School of Occupational therapy, University of Western Ontario; ${ }^{3}$ Knowledge Translation, Institute for Work and Health, Toronto, Ontario, Canada

\section{Abstract}

Women living with fibromyalgia consistently report experiencing a change in their lives in terms of stigma, inability to work, isolation from society and difficulty in managing their illness. Lack of understanding and knowledge about their disease has been linked to compromised health and quality of life. The aim of this study was to explore the experiences of information use of women living with fibromyalgia. A descriptive phenomenology was used for this study. Participants were identified through gatekeepers for women living with fibromyalgia across Canada. Data was collected via taperecorded interviews. The study was conducted in Canada between 2009-2010. Ten women (18 or older) participated in the research. Three essential themes emerged from the analysis that were vital to understand the unique experiences of women: i) understanding the need for information required to live with fibromyalgia, ii) struggling to meet vital and fundamental information needs and iii) transforming themselves to improve health and quality of life. Women living with fibromyalgia have vital and specific information needs and struggle to find and access appropriate information. They use diverse strategies in overcoming some of the challenges in accessing information. Most significantly, women draw on the information to make changes and to begin to coordinate their lives to live with fibromyalgia. For women living with fibromyalgia, the phenomenon of information use has a significant effect on their lives. Healthcare providers are perceived as an important source of information and need to be better informed, more prepared and dedicated to assisting women with their information needs.

\section{Introduction}

Fibromyalgia, chronic widespread musculoskeletal pain, is a common and increasingly diagnosed disease. People living with this disease, share some common co-morbidities such as migraine, irritable bowel syndrome, chronic fatigue syndrome, depression, mood and panic disorder. ${ }^{1}$ In developed countries such as Canada, $1.1 \%$ to $3.3 \%$ people are diagnosed with fibromyalgia. Among those diagnosed, the female to male ratio is six to one.,3 These high prevalence rates of fibromyalgia are also similar in the USA and Europe. ${ }^{4-6}$

There are few criteria for making a diagnosis of fibromyalgia, ${ }^{7,8}$ however, some argues that those criteria are inaccurate and patients are over diagnosed by physicians. ${ }^{9}$ As a result, there is no gold standard available for diagnosis and treatment for fibromyalgia. If people are not able to manage the condition for a number of years, it becomes a regular, permanent and underlying pain, which is difficult to manage, resulting in disability. ${ }^{10,11}$ Recognition of the disease has recently increased in parallel with research on the disorder. It has been predicted that fibromyalgia, like other arthritic diseases, will continue to increase in prevalence and that women will continue to be more predominantly affected by this disor$\operatorname{der}^{2,3,12,13}$

Due to the various co-morbidities associated with fibromyalgia, women suffer tremendously as a result of fibromyalgia.1,2,14,15 They experience life changes due to stigma, inability to work, isolation from society and not being able to manage their own condition.,16-22 For example, due to the chronic pain from fibromyalgia, women experience problems with movements, flexibility, work positions, adjustment to change in work roles in addition to reduced muscle strength and stamina. ${ }^{17,19,21}$ These problems restrict them in fulfilling their work and social roles ${ }^{20}$ which significantly impact on their quality of life. ${ }^{19,20,23,24}$ In addition, women experience further challenges due to a lack of access to information about their illness. Many studies that investigated the experience of living with fibromyalgia, reported that the loss of quality of life was increased due to a lack of awareness from healthcare providers and limited knowledge of the disease.4,16,17,19,25-27 Women report stigmatization in the workplace, including being accused of lying about their suffering to try to avoid their duties at work. ${ }^{20}$ In addition to these issues, women also experience a loss of freedom, threats to their integrity and struggle to achieve relief and understanding., ${ }^{4,16,17,22}$ Since healthcare professionals may not adequately understand the experience of fibromyalgia or how to best manage it, it could be anticipated that women
Correspondence: Lubna Daraz, School of Rehabilitation Science, Faculty of Health Sciences, McMaster University

1400 Main St.West. IAHS - 403. Hamilton, ON, L8S4L8, Canada.

Tel. +1.647.781.8536

E-mail: darazl@mcmaster.ca

Acknowledgement: this work was supported from a Doctoral Research Award (Frederick Banting and Charles Best Scholarship) from the CIHR; a Strategic Training Fellowship in Rehabilitation Research from the CIHR Musculoskeletal and Arthritis Institute; a S. Leonard Syme Training Fellowship from the Institute for Work \&Health; and a MSK Training Fellowship from the Ontario Rehabilitation Research Advisory Network to Lubna Daraz.

Key words: fibromyalgia, chronic pain, women's health, information use, coping, quality of life.

Contributions: LD, topic selecting, research questions formulating, literature reviewing, study designing, data collecting and analysis, manuscript drafting and revising; JCMD, SW, LS, JG, manuscrpt conception and design, data analysis, manuscript revising.

Conflict of interest:: the authors report no financial interests or potential conflicts of interest.

Received for publication: 22 June 2011.

Revision received: 22 November 2011.

Accepted for publication: 25 November 2011.

This work is licensed under a Creative Commons Attribution NonCommercial 3.0 License (CC BYNC 3.0).

(C) Copyright L.Daraz et al., 2011

Licensee PAGEPress, Italy

Rheumatology Reports 2011; 3:e15

doi:10.4081/rr.2011.e15

are challenged by a lack of adequate information. We might also suspect that given the controversial nature of fibromyalgia, women may be confronted with conflicting information or attitudes towards their health problem. For all chronic disease self-management, knowledge of the disease is a critical factor to obtain a better health and quality of life..$^{28-32}$ However, an examination of the experience of information use of women living with fibromyalgia has been overlooked. We refer to information use experiences as information needs, availability, preference, access and application issues that are important to address to help women manage and live with fibromyalgia. The purpose of this study was to explore the experiences of information use by women with fibromyalgia in order to understand the role of information in their day-today challenges of living with the illness. 


\section{Materials and Methods}

\section{Research design}

Given that this study was exploratory, we used a descriptive phenomenological approach to elaborate the values, meanings and the nature of the issues that women experience in trying to access and use information relevant to their condition and management of their disability. This approach allows pursuing the meaning of individual experiences through a dialogic process that extends beyond a simple interview and requires thoughtful presence on the part of the researcher. ${ }^{33}$ Moustakas's descriptive phenomenology is guided by phenomenological reduction, imaginative variation and synthesis of meaning and essences. ${ }^{34}$

\section{Recruitment and data collection}

We identified participants through gatekeepers (clinics, hospitals, physicians and fibromyalgia support groups) for women living with fibromyalgia across Canada. A purposeful criterion sample ${ }^{33}$ of ten women living with fibromyalgia was recruited for this study. Our inclusion criteria for participants were: i) women, ii) 18 years of age or older, iii) diagnosed with fibromyalgia for at least one year, iv) had symptoms prior to diagnosis, and v) able to communicate in English. The sample was based on adequacy and appropriateness $^{35,36}$ of the participants that captured the experience of information use of women with fibromyalgia. Participants were interviewed at locations based on their preferences of places where they felt comfortable. All of the interviews were tape recorded and transcribed verbatim. The length of the interviews was between 60 to $90 \mathrm{~min}$. Participants were asked questions about their experience of information needs, information access, information sources, online information and specific personal demographics.

\section{Data analysis}

For data analysis, we used Moustakas's modified method of the Stevick-Colaizzi-Keen analysis technique. ${ }^{34}$ Three of the authors (LD, LS and SW) independently analyzed transcriptions as part of the peer review process. Then, all the authors were involved in reviewing the themes and sub-themes along with the supporting quotes as a final step of the peer review process. The strategies that we used to achieve credibility of the findings were reflexivity, audit trail, and member checking ${ }^{33,37,38}$ throughout the study.

\section{Findings}

\section{Sample}

Participants were predominantly Caucasian and majority of them were 40 years of age or older which is consistent with the epidemiology of fibromyalgia. Eight of the participants were living with family as they were unable to take care of themselves; one was living with a roommate and one was living alone. The majority of the participants (seven) also reported that they were having difficulty making ends meet financially due to their illness. The participants were given pseudonyms to maintain their anonymity. As well, participants' exact age was not recorded based on their request. The diagnosis of fibromyalgia was not confirmed by a physician, rather participants self-reported as being diagnosed with fibromyalgia by a physician. Please see Table 1 for significant demographic characteristics of participants.

\section{The essential structure of the lived} experiences of information use

From the interview transcripts, one overarching theme, three major themes and 8 subthemes (Table 2) were extracted that were common for all women in this study. These themes represented the essences ${ }^{33}$ or the essential meaning of women's experience of

Table 1. Significant demographic characteristics of participants.

\begin{tabular}{|c|c|c|c|c|c|c|}
\hline $\begin{array}{l}\text { Participant } \\
\text { (pseudonym) }\end{array}$ & $\begin{array}{l}\text { Age } \\
\text { range }\end{array}$ & $\begin{array}{l}\text { Marital } \\
\text { status }\end{array}$ & $\begin{array}{l}\text { Level } \\
\text { of education }\end{array}$ & $\begin{array}{l}\text { Length } \\
\text { of symptoms }\end{array}$ & $\begin{array}{l}\text { Length } \\
\text { of diagnosis }\end{array}$ & Employment status \\
\hline A & $20-24$ & S & Some university & $6 y$ & $1 \mathrm{y}$ & Full time \\
\hline B & $25-29$ & M & College/some university & $15 y$ & $15 y$ & Unable to work \\
\hline $\mathrm{C}$ & $40-44$ & M & College/some university & $14 \mathrm{y}$ & $14 \mathrm{y}$ & Self-employed \\
\hline D & $45-49$ & D & College/some university & $6 y$ & $3 y$ & Full time \\
\hline E & $45-49$ & M & College/professional school & $12 \mathrm{y}$ & $2 \mathrm{y} 8 \mathrm{~m}$ & Unable to work \\
\hline $\mathrm{F}$ & $45-49$ & S & University/professional school & $27 y$ & $15 y$ & Unable to work \\
\hline G & 50-up & M & University (OT) & 1 y $2 \mathrm{~m}$ & $1 \mathrm{y}$ & Full time \\
\hline $\mathrm{H}$ & 50-up & M & College & $17 y$ & $5 y$ & Unable to work \\
\hline I & 50-up & M & University & $20 y$ & $2 y$ & Unable to work \\
\hline $\mathrm{J}$ & 50-up & M & College & $24 y$ & $19 y$ & Part time \\
\hline
\end{tabular}

Table 2. List of themes.

\begin{tabular}{|c|c|}
\hline \multicolumn{2}{|c|}{ Overarching theme. Overcoming struggles with information gaps } \\
\hline Major themes & Sub-themes \\
\hline Understanding the need for information required to live with fibromyalgia & $\begin{array}{l}\text { Overcoming uncertainty and suffering } \\
\text { Knowing I am not alone } \\
\text { Achieving a sense of control }\end{array}$ \\
\hline Struggling to meet vital and fundamental information needs. & $\begin{array}{l}\text { Struggling with the lack of support and information } \\
\text { from healthcare providers } \\
\text { Struggling to find or use reliable information }\end{array}$ \\
\hline Transforming themselves to improve their health and quality of life & $\begin{array}{l}\text { Exploring changes in coping strategies } \\
\text { Enhancing life style changes } \\
\text { Taking charge of health and life }\end{array}$ \\
\hline
\end{tabular}


information needs and challenges when trying to access and employ information relevant to their condition and knowledge of living with fibromyalgia.

\section{Overcoming struggles with information gaps}

The fundamental structure of information use evolved around the fibromyalgia information gaps. Women expressed that they did not have access to adequate information to understand and to manage their illness. They also shared that they endured a great deal of frustration and anxiety due to a lack of attention from healthcare providers and struggled to find reliable information. As a result, women described that they experienced stigma, injustice and agony while living with fibromyalgia and it was important for them to overcome the struggles with information gaps to achieve a healthy and meaningful life. The essential structure can be further described by its three major themes described below.

\section{Understanding the need for information} required to live with fibromyalgia

This experience was described by the following sub-themes: i) overcoming uncertainty and suffering, ii) knowing I am not alone and iii) achieving a sense of control.

Participant A was a young woman who lived with the symptoms of fibromyalgia for five years before diagnosis and was a resident of a city where there was a lack of support available to her. She did not have access to appropriate information which made her feel uncertain about the nature of her disease and expressed her frustration as: I think it would be nice to know what to expect so that you are not always confused if you have a new pain, you need to be able to say okay, is this part of fibromyalgia or is this something else. (Participant A)

She and others also wanted to know the likely outcomes of fibromyalgia, for example, potential symptoms, changes in health, or changes in life style so that they understood the consequences of the disease.

These women also expressed that it was helpful for them to become acquainted with other people who were suffering from fibromyalgia and to connect with them since they experienced negative attitudes and did not receive the support or recognition among healthcare providers, family, friends, employers and co-workers. Contact with others gave Participant E, a sense of hope as she felt that she was not alone in her suffering from fibromyalgia. She reflected on these feelings of isolation as: ... to find out, there are other people obviously suffering from this debilitating condition as well to find out how they are dealing with it. It is good to reflect the fact that I'm not alone. (Participant $\mathrm{E}$ )

Due to the burden of the illness, half of the participants were unable to work and dis- cussed that they needed information to overcome the challenges with the daily sufferings and to achieve a sense of control over their illness. All of the women shared that the more information they found, the easier it was for them to manage their illness and to live with fibromyalgia.

I mean that's the whole gist of this is to get as much information to improve or better the quality of your life. (Participant D)

\section{Struggling to meet vital and fundamental information needs}

Vital and fundamental information for women was specific and reliable information about fibromyalgia. This theme included two sub-themes: i) struggling with the lack of support and information from healthcare providers and ii) Struggling to find or use reliable information.

The experience of finding information was very challenging for women in this study. It was very difficult for them to sort out and make sense of information due to numerous barriers. Women expressed that they had to struggle with the lack of information about fibromyalgia as there was no information provided to them by their healthcare providers. They were left on their own to search for information.

When I was first diagnosed there was nothing. I had to look everything up myself, seek out the information; nothing was given to me lby my physician]. (Participant $\mathrm{J}$ )

Lack of support and differences of opinions among healthcare providers was a major barrier to access information that could help them understand their illness and to make decisions about their health. Women also felt that healthcare providers themselves did not have enough information about fibromyalgia and were unable to communicate with them.

I mean for myself being diagnosed, having not previously heard anything about this illness, to be experienced with all kinds of things that are normal and just taking yoga class. I mean what do you do? It llack of information from healthcare provider] does not give you any means to cope in your daily life, it does not prepare you to make life style changes, and it does not give you any kind of explanation. You don't know what to expect, you don't understand what you are feeling and you really feel like your healthcare provider does not care. (Participant A)

Women also shared that they had essential needs for specific information about fibromyalgia. These fundamental information needs were vital for them to understand what was going on with their health and how to deal with their illness. They needed information about diagnosis, treatment options, medications, exercises, diet/food, alternative therapies, specialists, coping strategies, support groups and new research on fibromyalgia.

Majority of the women discussed that they used different strategies to find information. One strategy was searching for the types of information described above through diverse sources such as the library, Internet, health magazines, books, and support groups. Women also drew on their personal capacities of knowledge and experience in finding sources to access information.

However, all of the women in this study shared their frustration about a lack of access to relevant information through the above sources and described that their process of accessing information was ongoing. For the most part, the information that was available to them was not reliable and women wanted to have information about fibromyalgia combined in a package that was up-to-date, relevant, consistent, accurate, easy to read and easy to access that came from reliable sources.

Transforming themselves to improve health and quality of life

The ultimate goal of finding and accessing relevant information for women with fibromyalgia was to draw on the information they were able to find. All of the women thus repeatedly conveyed the message that they constantly needed to filter the relevance of the information themselves so that they could make life style changes to transform their lives. The more information women received about fibromyalgia, the more they were able to act as agents of change for themselves in enhancing their lives with less suffering and more participation.

I use information to improve everything. Anything that I read that sounds like it might be helpful, I will always try and the more information you have the better it is. It's very very important especially because fibromyalgia is not an illness where they are necessary going to be able to cure you. So the more information you have about your treatment options and the more information you have about your illness, you may experience less suffering, you may be able to help yourself. (Participant F)

\section{Discussion}

Women in this study provided a significant reflection of the essences of the struggles in their experience of information use when trying to find and access the information they needed to help them live with fibromyalgia. The major findings of this study indicated that women 18 or older living with fibromyalgia have essential needs for information for managing their illness which prompted them to seek out information. These findings are discussed relevant to advancing the literature and 
implications for practice and research.

The findings are consistent with other studies investigating information needs for women with fibromyalgia or other chronic conditions. ${ }^{29,30,39}$ This study furthers the understanding of the nature and sources of the struggle to find relevant and applicable information. For instance, findings suggest that the challenges with the suffering and daily life disruptions of pain along with the uncertainties about the nature of fibromyalgia underscore the need for information. In addition, lack of consistent or credible information and the differences in health care provider views about fibromyalgia make it difficult for these women to personally sort out and make sense of information for living with fibromyalgia. Many of the women feel isolated and alone in their attempts to understand the meaning of fibromyalgia in the realm of daily life. The experiences of these women are consistent amongst participants with different age ranges. These findings thus highlight the need for greater sensitivity and compassion about the extent of the frustrations that arise with experiencing a poorly understood health problem and its unpredictable nature. Further to this, efforts are needed to provide relevant information in a timely manner that can assist women in managing their illness.

This study offers insights into a breadth of the types of information such as diagnosis, treatment options, medications, exercises, diet/food, alternative therapies, specialists, coping strategies, support groups and research that are instrumental to helping these women live with fibromyalgia. Findings also suggest that due to the idiosyncratic nature of the impact of fibromyalgia on daily life the need for information is unique for each woman. As well, the need is ongoing as women begin to use information, learn new ways of coping or doing things, and experience changes over time with fibromyalgia. Developing information resources that target the type of information needed may be useful to help women tailor their information use. Further study on the ways women use resources of information is needed to ensure more equitable access to the knowledge that women need.

Many of the women in this study who have many years of living with fibromyalgia share strategies in overcoming some of the challenges in accessing information. One of the ways women access information is through the Internet. This is consistent with Crooks' ${ }^{29}$ findings where women with fibromyalgia in her study expressed their interest of using online information to inform their doctor-patient interactions. However, further to our findings, it is evident that these women search for information across different sources by interacting and connecting with others to share and learn information. The extent to which these women search for and struggle to access information suggests that there is a need to offer improved resources and formats. These will help women to access the information they need such as resources for peer support and connections as well as easily accessible written forms of information. In addition, given that these women have extensive experience of finding and utilizing information to further their knowledge, healthcare providers need to include women with fibromyalgia in the development and design of programs intended to transfer fibromyalgia information to them.

One of the most striking findings of this study is the extent to which women draw on the information to make changes and to begin to coordinate their lives to manage fibromyalgia. Others have also found that information gives women a sense of control and power to make changes in their lives. ${ }^{31}$ For instance, in this study, women despite their age, not only access various sources but they also begin to filter the relevance of the information to make life style changes. This step supports these women in becoming agents of change in managing to cope with the uncertainties and to alter their eating and exercise regimes. Helping women to move toward applying knowledge and action through using and interpreting the relevance of information is consistent with findings of others. ${ }^{39}$ This finding has implications for health care providers in working with women to foster and support them in achieving an understanding of how to live, act upon and manage daily life with fibromyalgia. More efforts are needed to assist health care providers in supporting the transfer of relevant knowledge to their patients.

This study was carried out with women who are predominantly Caucasian and have college or higher level of education. Findings reflect only the information use experience for this group of women and cannot be assumed to apply to other women with different cultural and educational backgrounds. In addition, our study was carried out with ten women. We cannot argue that our findings reflect on the information use experience for all women living with fibromyalgia. However, the relevance of these findings may inform ways to address and to investigate further the development of effective information sources for all women living with fibromyalgia.

\section{Conclusions}

For women living with fibromyalgia, the phenomenon of information use has a significant effect on their lives. This study provides a deeper understanding of the day-to-day challenges of the experience of information use by women (18 or older) living with fibromyalgia.
There are two agents that emerged in this study who are able to make positive changes in women's life. First, are the women themselves, if they are provided with relevant information, they are able to make changes in their own health and life. The second is the healthcare providers. If we can increase their understanding of what women need and the strategies women use to meet their needs, this knowledge will help healthcare providers to act as a better knowledge broker thus improving their practice for women living with fibromyalgia.

\section{References}

1. Hudson JI, Goldenberg DL, Pope HG Jr, et al. Comorbidity of fibromyalgia with medical and psychiatric disorders. Am J Med 1992;92:363-7.

2. McNally JD, Matheson DA, Bakowsky VS. The epidemiology of self-reported fibromyalgia in Canada. Chronic Dis Can 2006; 27:9-16.

3. White KP, Speechley M, Harth M, Ostbye T. The Lodon fibromyalgia epidemiology study: the prevalence of fibromyalgia syndrome in London, Ontario. J Rheumatol 1999;26:1570-6.

4. Kool MB, Middendor, HV, Lumley MA, et al. Lack of understanding in fibromyalgia and rheumatoid arthritis: the Illness Invalidation Inventory $\left(3^{*} \mathrm{I}\right)$. Ann Rheum Dis 2010;69:1990-5.

5. Neumann L, Buskila D. Epidemiology of Fibromyalgia. Curr Pain Headache Rep 2003;7:362-8.

6. Helmick CG, Felson DT, Lawrence RC, e al. Estimates of the prevalence of arthritis and other rheumatic conditions in the United States. Part I. Arthritis Rheum 2008;58:15-25.

7. Wolfe F. Fibromyalgia: on criteria and classification. J Musculoskel Pain 1994;2:24-5.

8. Jain AK, Carruthers BM, Marjorie IS van de, e al. Canadian clinical working case definition, diagnostic and treatment protocols- a consensus document. J Musculosk Pain 2003;11:3-107.

9. Fitzcharles MA, Boulos P. Inaccuracy in the diagnosis of fibromyalgia syndrome: analysis of referrals. Rheumatol 2003;42: 263-7.

10. Henriksson CM. Long-term effects of fibromyalgia on every-day life. A study of 56 patients. Scand J Rheumatol 1994;23: 36-41.

11. Kennedy M, Felson DT. A prospective longterm study of fibromyalgia syndrome. Arthritis Rheum 1996;39:682-5.

12. Arthritis.ca.Toronto: The Arthritis Society. Available from: http://www.arthritis.ca. Accessed on 2011 Feb 25. 
13. Branco JC, Bannwarth B, Failde I, et al. Prevalence of Fibromyalgia: a Survey in Five European Countries. Semin Arthritia Rheum 2010;39:448-53.

14. Williams DA, Clauw DJ. Understanding fibromyalgia: Lessons from the broader pain research community. J Pain 2009;10:777-91.

15. Weir PT, Harlan GA, Nkoy FL, et al. The incidence of fibromyalgia and its associated comorbidities: a population-based retrospective cohort study based on international classification of diseases, 9th revision codes. J Clin Rheumatol 2006;12:1248.

16. Kool MB, van Middendorp H, Boeije HR, Geenen R. Understanding the lack of understanding: invalidation from the perspective of the patient with fibromyalgia. Arthritis Rheum 2009;61:1650-6.

17. Lempp HK, Hatch SL, Carville SF, Choy EH. Patients' experiences of living with and receiving treatment for fibromyalgia syndrome: a qualitative study. BMC Musculoskelet Disord 2009;10:124.

18. Bennett MR, Jones J, Turk CD, et al. An internet survey of 2,596 people with fibromyalgia. BMC Musculoskelet Disord 2007;8:27.

19. Cudney SA, Butler MR, Weinert C, SullivanT. Ten rural women living with fibromyalgia tell it like it is. Holist Nurs Pract 2002;16:35-45.

20. Asbring P, Narvanen A. Women's experience of stigma in relation to chronic fatigue syndrome and fibromyalgia. Qual Health Res 2002;12:148-60.

21. Liedberg GM, Henriksson CM. Factors of importance for work disability in women with fibromyalgia: an interview study.
Arthritis Rheum 2002;47:266-74.

22. Soderberg S, Lundman B, Norberg A. Struggling for dignity: the meaning of women's experience of living with fibromyalgia. Qual Health Res 1999;9:57587.

23. Galeotti N, Ghelardini C, Zoppi M, et al. Reduced functionality of $\mathrm{Gi}$ proteins as a possible cause of fibromyalgia. J Rheumatol 2001;28:2298-304.

24. Råheim M, Håland W. Lived experience of chronic pain and fibromyalgia: women's stories from daily life. Qual Health Res 2006;16:741-61.

25. Madden S, Sim J. Creating meaning in fibromyalgia syndrome. Soc Sci Med 2006;63:2962-73.

26. Cunningham MM, Jillings C. Individuals' descriptions of living with fibromyalgia. Clinic Nurs Res 2006;15:258-73.

27. Koulil SV, Kraaimaat FW, Lankveld WV, et al. A patient's perspective on multidisciplinary treatment gain for fibromyalgia: An indicator for pre-post treatment effects? Arthritis Rheum. 2009;61:1626-32.

28. Wagner EH, Austin BT, Davis C, et al. Improving Chronic Illness Care: Translating Evidence into Action Interventions that encourage people to acquire self-management skills are essential in chronic illness care. Health Affairs 2001;20:6.

29. Crooks VA. I go on the Internet; I always, you know, check to see what's new chronically ill women's use of online health information to shape and inform doctor-patient interactions in the space of care provision. ACME: An Internet E-Journal for Criti Geog 2006;5:50-69.

30. Hogan PT, Palmer LC. Finding and using medical information. "Information work" and chronic illness: interpreting results from a nationwide survey of people living with HIV/AIDS. Proceedings of the American Society for Information Science and Technology 2006;42.

31. Warner D, Procaccino DJ. Toward wellness: women seeking health information. J American Soc Inform Sci Tech 2004;55:709-73.

32. Deane KA, Degner LF. Information needs, uncertainty, and anxiety in women who had a breast biopsy with benigh outcome. Cancer Nurs 1998;21:117-26.

33. Pope C, Mays N. Researching the parts that other methods cannot reach: an introduction to qualitative methods in health and health services research. BMJ 1995; 311:42-5.

34. Moustakas C. Phenomenologocal research methods. Sage Publications. Thousand Oaks: California 1994.

35. Streubert SHJ, Rinaldi CD. Qualitative research in nursing: advancing the humanistic perspective. 3rd ed. Lippincott Williams Wilkins Books, 2003.

36 . Morse J. On the evaluation of qualitative proposals. Qual Health Res 1991;1:147-51.

37. Creswell WJ. Qualitative enquiry and research design: choosing among five approaches. Thousand Oaks, CA: SAGE, 2007.

38. Cohen MZ, Kahn DL, Steeves RH. Hermeneutic phenomenological research. Thousands Oaks, CA: SAGE, 2000.

39. Shaw L, Pye K, Dodman J. Client insights on knowledge use and access in return to work. Cana J Occup Therapy 2009;76:35967. 